\title{
CLSI BROTH MICRODILUTION METHOD FOR TESTING SUSCEPTIBILITY OF MALASSEZIA PACHYDERMATIS TO THIABENDAZOLE
}

\author{
Patrícia da Silva Nascente ${ }^{1 *}$; Ana Raquel Mano Meinerz ${ }^{1}$; Renata Osório de Faria ${ }^{1}$; Luiz Filipe Damé Schuch²; \\ Mário Carlos Araújo Meireles²; João Roberto Braga de Mello ${ }^{1}$
}

${ }^{1}$ Programa de Pós Graduação em Ciências Veterinárias, Universidade Federal do Rio Grande do Sul, Porto Alegre, RS, Brasil; ${ }^{2}$ Departamento de Veterinária Preventiva, Faculdade de Veterinária, Universidade Federal de Pelotas, Pelotas, RS, Brasil

Submitted: October 18, 2007; Returned to authors for corrections: January 10, 2008; Approved: April 08, 2009.

\begin{abstract}
Thiabendazole, classified as antiparasitic and also used as an antifungal drug, can be found as otological solution indicated for treatment of parasitic and fungal external otitis in small animals. Malassezia pachydermatis is a yeast recognized as a normal inhabitant on the skin and mucous membranes of dogs and cats. However, it is considered an opportunistic agent that causes external otitis and dermatitis in these animals. The aim of this study was to evaluate the in vitro effect of thiabendazole against 51 isolates of $M$. pachydermatis using the CLSI Broth Microdilution method that has been adapted for this yeast species (NCCLS, 2002). Based on this test, the Minimum Inhibitory Concentrations (MIC) of thiabendazol was calculated. Subsequently, the susceptibility of each isolate against this antifungal was determined. It was observed that the MIC of thiabendazole against $M$. pachydermatis ranged from 0.03 to $>4 \mu \mathrm{g} / \mathrm{mL}$. A total of $13.7 \%$ of the isolates were found to be resistant, $47.1 \%$ were intermediate and $39.2 \%$ were sensitive to the drug. The rate of resistance of the yeasts against thiabendazole was similar to the results previously obtained with other antifungals, while the adapted broth microdilution technique used in this study proved to be efficient.
\end{abstract}

Key words: Malassezia pachydermatis, Minimum Inhibitory Concentration, thiabendazole

\section{INTRODUCTION}

The need for an antihelmintic, with a broad spectrum of antiparasitic effect, highly efficient, with good safety limits and that would also be versatile in its administration, promoted a study of hundreds of benzimidazole compounds. Thiabendazole was the first compound that fulfilled all of those requirements with an extraordinary performance $(26,27)$. Its in vitro antifungal activity was observed against Blastomyces spp, Aspergillus spp, Fusarium spp, Penicillium spp and Trichophyton spp, although there have been controversies regarding its effect against some yeasts, such as Candida sp. $(26,30)$.

Malassezia pachydermatis is a yeast that is considered a normal inhabitant and an opportunistic pathogen of the external ear canal of dogs and cats, and it can also be found on the skin and in the rectum, anal sacs and vagina of these animals $(2,3,4,5)$. This yeast is one of the most frequent microorganisms associated with external otitis in dogs $(9,19)$. In recent years, studies have also reported $M$. pachydermatis as the cause of canine dermatitis $(4,6,21,24,28)$.

The appearance of the clinical manifestations of malasseziosis indicates an alteration in the balance between the commensal yeast and its host. The onset of clinical disease occurs when there is excessive multiplication of $M$. pachydermatis due to alterations in the defense mechanisms of the host. An increase in the number of M. pachydermatis cells is favored when there is a modification in the microenvironment, such as excessive production of cerumen, after therapy with antibiotics or corticoids $(17,24)$ and also with

*Corresponding Author. Mailing address: Universidade Federal de Pelotas, Faculdade de Veterinária, Campus Universitário s/n. CEP: 96010-900. Capão do Leão, RS, Brasil. Tel.: +55 53 32279876; Fax: +55 53 32759004. E-mail: patsn@ bol.com.br 
concomitant primary diseases, such as hypersensitivity to food, flea bites and/or atopy, pyodermitis, demodicosis and endocrine problems (hyperadrenocorticism, hyperthyreodism, diabetes mellitus). Therefore, malasseziosis is an infection frequently associated with concomitant primary diseases $(3,17)$.

Only one study of the in vitro activity of thiabendazole against $M$. pachydermatis has been carried out (18). This study used the agar diffusion method for testing this and other antifungal drugs against $M$. pachydermatis. Thiabendazole had its in vitro inhibitory activity confirmed by this technique, without the calculation of the Minimum Inhibitory Concentration (MIC).

This drug has been used in suspension as a fungicide for poultry breeding and livestock farming, mainly in the prevention of aspergilosis, without showing any incompatibility. Currently, an otological solution of thiabendazole is recommended for the treatment of mycoses caused by Microsporum canis, $M$. gypseum, Trichophyton mentagrophytes and T. equinum. In Brazil, the otological solution of this drug is found in products such as Otoden plus ${ }^{\circledR}$ (Vetbrands) and Otoneodexa® (Usinas Quimicas Brasileiras) for the treatment of canine external otitis. This drug is used in association with neomycin and dexametazone, which amplify the spectrum of action of Thiabendazole, enabling it to be effective for the treatment of bacterial, fungal and inflammatory canine external otitis (12), including those infections caused by $M$. pachydermatis, which is recognized as a normal inhabitant and is also considered an opportunistic agent that causes external otitis and dermatitis $(1,5,16,23)$.

In vitro testing of antimicrobial susceptibility is of great importance. Some authors recommend the evaluation of antifungal sensitivity through the use of antimycograms in special clinical conditions, such as cases of therapeutic failure, which is quite common in cases of canine external otitis and dermatitis exacerbated by $M$. pachydermatis $(1,8,14)$.

The aim of this study was to use the broth microdilution method (22) to test the activity of thiabendazole against 51 isolates of M. pachydermatis obtained from clinical cases of canine external otitis.

\section{MATERIAL AND METHODS}

All strains, collected with sterile swabs from canine ear canals, were cultured in Sabouraud dextrose agar medium with chloramphenicol and cycloheximide, kept at $32^{\circ} \mathrm{C}$ for ten days, and their macroscopic characteristics were observed daily. Cell morphology was observed through the use of colony smears, which were stained with Gram stains and then characterized (15).

The National Committee for Clinical Laboratory Standards (22), currently known as the Clinical and Laboratory Standards Institute (CLSI) recently published two standardized methods for broth microdilution for use in antifungal testing, the M27A2 and the M38P. The NCCLS Broth Microdilution (BM) method adapted for M. pachydermatis was performed by Eichenberg et al. and Nascente et al. $(9,19)$ according to the M27A2 document (22) and thiabendazole recommendations. This methodology was used to evaluate the susceptibility of 51 isolates of M. pachydermatis against thiabendazole, with a few modifications in the method for this specific antifungal. The antifungal susceptibility test by BM was carried out in sterile microdilution plates (Nuclon ${ }^{\circledR}$ ) with 96 flat bottomed wells, composed of eight series identified from $\mathrm{A}$ to $\mathrm{H}$, each one with twelve wells.

The $M$. pachydermatis isolates were suspended in saline solution with the turbidity adjusted to level 1 of the McFarland scale. After that, they were diluted in Sabouraud broth medium and a volume of $100 \mu \mathrm{l}$ was dispensed into the wells, which contained $100 \mu \mathrm{l}$ of twice the final concentrations of the antifungal. Thus, the final dilution of the starting inoculum was $1: 10$.

From the stock-solution of the drug $(1.6 \mathrm{mg} / \mathrm{mL})$, diluted according to the methodology recommended by the NCCLS/ CLSI (22), ten successive dilutions were prepared with a concentration 10 times greater than the final solution of thiabendazole. The dilutions were further diluted to $1: 5$ in Sabouraud dextrose broth with chloranphenicol and $100 \mu \mathrm{l}$ aliquots were sequentially dispensed into the microdilution plates, filling the wells in the columns numbered from 1 to 10 .

The columns 11 and 12 were reserved as controls. The positive control was composed of $100 \mu \mathrm{l}$ of Sabouraud dextrose agar and $100 \mu \mathrm{l}$ of the half-inoculum solution. The negative control was composed of $200 \mu \mathrm{l}$ of the same culture medium. The plates were incubated at $37^{\circ} \mathrm{C}$ for $72 \mathrm{~h}$. The readings were made visually, comparing the growth of the yeast in the wells numbered one to ten (with varying concentrations of antifungal) with the wells that had the positive control (cavity 11). The lowest concentration that produced a significant inhibition (around 50\%) of the growth of the yeast in comparison with the positive control was identified as the MIC.

\section{RESULTS AND DISCUSSION}

The MIC of thiabendazole, observed through the BM method against 51 isolates of $M$. pachydermatis ranged from 0.03 to $>4 \mu \mathrm{g} / \mathrm{mL}$ (Fig. 1) with a mean MIC of $3.67 \mu \mathrm{g} / \mathrm{mL}$ and a mode of $4 \mathrm{mg} / \mathrm{mL}$. In the current literature there are no studies of thiabendazole and the adapted BM method to compare these results.

After observation of the MIC, M. pachydermatis isolates were classified as sensitive (S), intermediate (I) and resistant (R), according to the criteria proposed by Colombo et al. (7) and the results of the MIC50 and MIC90: S = MIC-strain < MIC-50\%; $\mathrm{I}=$ MIC-50\% > MIC- strain $<$ MIC- $90 \%$; $\mathrm{R}=$ MIC- 
strain > MIC-90\%. Resistance was verified in seven (13.7\%) isolates of the yeast, intermediate sensitivity in $24(47.1 \%)$ isolates and sensitivity in $20(39.2 \%)$ strains (Table 1 ).

However, when comparing the susceptibility of $M$. pachydermatis against thiabendazole with other antifungals, the MIC has different values and the percentage of resistant isolates to this drug.

The NCCLS/CLSI methods are indicated for some yeasts and filamentous fungi against the antifungals ketoconazole, fluconazole, itraconazole, amphotericine and flucitosine. The NCCLS (22) recommends the use of RPMI 1640 in antifungal tests with yeasts (Candida spp. and Cryptococcus spp.), although it has not yet been used with the Malassezia species (25). Other authors $(9,19)$ used Sabouraud dextrose liquid instead of RPMI 1640 in the BM method, and reported a better growth of the yeasts.

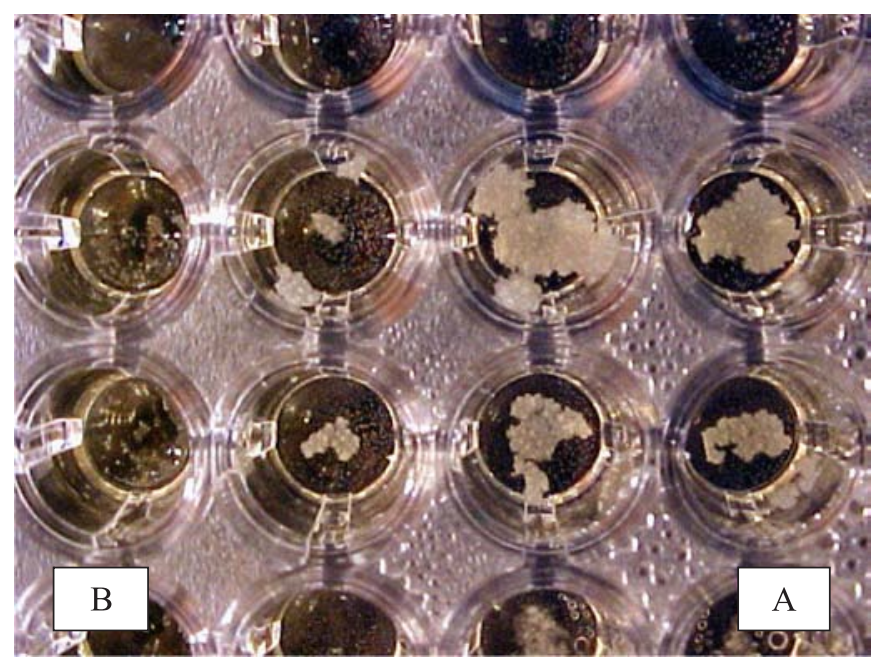

Figure 1. Microdilution plate used for Broth Microdilution method with thiabendazole against Malassezia pachydermatis isolated from canine external otitis, showing the wells with growth (A) and the ones without growth (B) of the yeast (negative control).

Table 1. Minimum Inhibitory Concentration (MIC) of thiabendazole against 51 isolates of $M$. pachydermatis obtained from canine external otitis.

\begin{tabular}{|c|c|c|c|}
\hline \multirow{2}{*}{ Antifungal } & \multicolumn{3}{|c|}{ Susceptibility (mg/mL) } \\
\hline & $\mathrm{S}^{*}$ & $I^{*}$ & $\mathrm{R}^{*}$ \\
\hline Thiabendazole & $<3.055$ & 3.055 to 7.154 & $>7.154$ \\
\hline
\end{tabular}

The M27A2 is a reference protocol that was written to provide consensus on the evaluation of the susceptibility of yeasts against antifungals. However, the method includes invasive yeasts, such as Candida sp. and C. neoformans var. neoformans, and does not standardize the evaluation of other yeasts. Several developed countries have Committees of Standardization. The NCCLS (U.S.A.) is one of the most active. The M27A2 document (22) is not appropriate for Malassezia, because it is lipodependent yeast. RPMI1640 is not an appropriate culture medium for Malassezia because it is not supplemented with lipids (13). Therefore, methods described in the literature need to be frequently adapted. The methodology described by Eichenberg et al. (9) and Nascente et al. (19) was followed in the current study. Eichenberg et al. (9) compared the RPMI1640 medium with Sabouraud dextrose medium and observed a better isolation of $M$. pachydermatis in RPMI1640 (31).

The antifungals reported in the CLSI document (22) included the azoles (itraconazole, fluconazole and ketoconazole), 5-flucitosine and amphotericine. Thiabendazole is not mentioned in that document. Therefore, the methodology had to be adapted for the current work.

For the BM method, a dilution of the yeast in a proportion of $1: 10$, from a suspension of approximately $1-5 \times 10^{6} \mathrm{UFC} / \mathrm{mL}$, was used according to the studies carried out by Eichenberg $e t$ al. (9) and Nascente et al. (19). Excellent results for the growth of Malassezia sp. were obtained. Other authors successfully used the same dilution in an experiment with $M$. pachydermatis isolates and the broth macrodilution method (29).

The interval used for reading the test was $72 \mathrm{~h}$, in accordance with the intervals suggested other authors, which recommend $24 \mathrm{~h}$ for Candida spp. and 48-72 $\mathrm{h}$ for Cryptococcus neoformans $(11,22)$. The same methodology used by Nascente et al. (19) was also followed, as they observed a significant difference when the reading was carried out after $72 \mathrm{~h}$, when the best fungal growth was observed. The results observed after $72 \mathrm{~h}$ was used for the calculation of the mean MIC.

Broth microdilution testing of Malassezia is under development; therefore, there is controversy as to what particular broth medium will support sufficient growth to reliably and reproducibly give MICs. In the single previous study examining thiabendazole and $M$. pachydermatis, Lorenzini et al. (17) reported that the substances were effective in inhibiting the growth of these organisms, but that there was no relation between in vitro activity and commercial formulations of the antimicrobials. The fact that this drug is not used by the veterinary community as a sole drug for the treatment of disease underscores its insufficiency. Furthermore, there was no attempt to experimentally compare the current results with those from methods used and published in internationally peer reviewed journals or compare with drugs having MICs defined by these methods. 
The M27A2 method (22), adapted and used for the MIC evaluation of thiabendazole against $M$. pachydermatis, was satisfactory, showing similar results to the ones obtained by other tests carried out with other antifungal drugs regarding susceptibility. The antifungal thiabendazole showed MIC values compatible with those observed with other drugs, with similar rate of resistant yeasts.

\section{RESUMO}

\section{CLSI método de Microdiluição em Caldo para teste de suscetibilidade da Malassezia pachydermatis frente ao tiabendazol}

Tiabendazol, um fármaco classificado como antiparasitário e também usado como antifúngico, pode ser encontrado como solução otologica indicada no tratamento da otite externa parasitária e fungica em pequenos animais. Malassezia pachydermatis é uma levedura considerada habitante normal da pele e das mucosas de cães e gatos. Entretanto, considerase um agente do oportunista causador de otite externa e dermatite nestes animais. A finalidade deste estudo foi avaliar o efeito in vitro do tiabendazol frente a 51 amostras de $M$. pachydermatis através do método CLSI de Microdiluição em Caldo adaptado para esta espécie de levedura (NCCLS, 2002). Baseado neste teste calculou-se as Concentrações Inibitórias Mínimas (CIM) do tiabendazol e, subseqüentemente, foi detectada a suscetibilidade de cada amostra frente a este antifungico. Observou-se que a CIM do tiabendazol frente a M. pachydermatis variou de 0,03 a $>4 \mu \mathrm{g} / \mathrm{mL}$. Estas amostras foram classificadas em resistente $(13,7 \%)$, sensibilidade intermediária $(47,1 \%)$ e sensível $(39,2 \%)$. A resistência da levedura frente ao tiabendazol mostrou similaridade com resultados anteriormente observados com outros antifúngicos e a adaptação da técnica de Microdiluição em Caldo utilizada mostrou-se eficiente.

Palavras-chave: Malassezia pachydermatis, Concentração Inibitória Mínima, tiabendazol.

\section{REFERENCES}

1. Ashbee, H.R. (2007). Update on the genus Malassezia. Med. Mycol., 45 (4): 287-303.

2. Bond, R.; Saijonmaa-Koulumies, L.E.; Lloyd, D.H. (1995). Population sizes and frequency of Malassezia pachydermatis at skin and mucosal sites on healthy dogs. J. Small Anim Pract., 36 (4): 147-50.

3. Bond, R.; Lamport, A.I.; Lloyd, DH. (2000). Colonisation status of Malassezia pachydermatis on the hair and in the hair follicle of healthy beagle dogs. Res. Vet. Sci., 68 (3): 291-3.

4. Bond, R.; Habibah, A.; Patterson-Kane, J.C.; Lloyd, D.H. (2006). Patch test responses to Malassezia pachydermatis in healthy dogs. Med. Mycol., 44 (2): 175-84.

5. Cafarchia, C.; Gallo, S.; Romito, D.; Capelli, G.; Chermette, R.; Guillot, J.; Otranto, D. (2005). Frequency, body distribution, and population size of Malassezia species in healthy dogs and in dogs with localized cutaneous lesions. J. Vet. Diagn. Invést., 17, 316-322.

6. Chen, T.A.; Halliwell, R.E.; Pemberton, A.D.; Hill, P.B. (2002). Identification of major allergens of Malassezia pachydermatis in dogs with atopic dermatitis and Malassezia overgrowth. Vet. Dermatol, 13 (3): 141-50.

7. Correa, W.; Correa, C. (1992). Enfermidades infecciosas dos mamíferos domésticos, 2 Edition. MEDSI, Rio de Janeiro.

8. Crespo, M.J.; Abarca, M.L.; Cabanes, F.J. (2002). Occurrence of Malassezia spp. in the external ear canals of dogs and cats with and without otitis externa. Med. Mycol., 40 (2): 115-21.

9. Eichenberg, M.; Appelt, C.E.; Berg, V.; Muschner, A.; Nobre, M.; Mata, D.; Alves, S.; Ferreiro, L. (2003). Suscetibility of Malassezia pachydermatis to azole antifungal agent evoluate by a new broth microdiluition method. Acta Sci. Vet., 31, 75-80.

10. ETEST (1994). AB BIODISK Technical Guide 4b, Antifungal susceptibility testing of yeasts (Solna, Sweden).

11. Faria, G. (2002). Antifúngicos In: Andrade, S.F. (Ed.) Manual de Terapeutica Veterinária. Roca, São Paulo, p. 59-70.

12. Garau, M.; Jr, P.M.; Palacio, A. (2003). In vitro susceptibilities of Malassezia species to a new triazole Albaconazol (UR-9825) and others antifungals compounds Antimicrob age chemother, 47, 2342-2344.

13. Greene, G. (1998). Infectious Diseases of the Dog and Cat, 2 Edition. W. B. Sauders, Philadelphia.

14. Gueho, E.; Midgley, G.; Guillot, J. (1996). The genus Malassezia with description of four new species. Antonie Van Leeuwenhoek., 69 (4): $337-55$

15. Guillot, J.; Bond, R. (1999). Malassezia pachydermatis: a review. Med. Mycol., 37, 295-306.

16. Harvey, R. (2001). Ear Diseases of the Dog and Cat. Ames: Iowa State University Press.

17. Lorenzini, R.; Mercantini, R.; De Bernardis, F. (1985). In vitro sensitivity of Malassezia spp. to various antimycotics. Drugs Exp Clin Res., 11, 393-395.

18. Nascente, P.S.; Nobre, M.O.; Meinerz, A.R.M.; Gomes, F.R.; Souza, L.L.; Meireles, M.C.A. (2004). Ocorrência de Malassezia pachydermatis em cães e gatos. Revista Brasileira de Medicina Veterinária, 26 (2): 79-82.

19. Nascente, P.; Nobre, M.; Schuch, L.; Lucia Jr., T.; Ferreiro, L.; Meireles, M. (2003). Evaluation of Malassezia pachydermatis antifungal susceptibility using two different methods. Braz. J. Microbiol., 34 , 359-362.

20. Nardoni, S.; Mancianti, F.; Rum, A.; Corazza, M. (2005). Isolation of Malassezia species from healthy cats and cats with otitis. J. Feline Med., Surg., 7 (3): 141-5.

21. Nardoni, S.; Dini, M.; Taccini, F.; Mancianti, F. (2007). Occurrence, distribution and population size of Malassezia pachydermatis on skin and mucosae of atopic dogs. Vet. Microbiol., 122 (1-2): 172-7.

22. NCCLS (2002). M27-A2. In National Committee for Clinical Laboratory Standards. Reference method for broth dilution antifungal susceptibility testing of yeasts: proposed standard.

23. Nobre, M.; Castro, A.; Nascente, P.; Ferreiro, L.; Meireles, M. (2001). Ocurrency of Malassezia pachydermatis and other infectious agents as cause of external otitis from Rio Grande do Sul state, Brazil (1996/1997). Braz. J. Microbiol., 32, 245-249.

24. Plant, J.D.; Rosenkrantz, W.S.; Griffin, C.E. (1992). Factors associated with and prevalence of high Malassezia pachydermatis numbers on dog skin. J. Am. Vet. Med. Assoc., 201 (6): 879-82.

25. Rex, J.; Pfaller, M.; Walsh, T.; Chaturvedi, V.; Espinel-Ingroff, A.; Ghannoum, M.; Gosey, L.; Odds, F.; Rinaldi, M.; Sheehan, D.; Warnock, D. (2001). Antifungal Susceptibility Testing: Practical Aspects and Current Challenges. Clin. Microbiol. Ver., 14, 643-658.

26. Roberson, E.L. (1983). Drogas usadas para nematódios, In: Meyer Jones, L.; Booth, N.N.; Mcdonald, L. Farmacologia e Terapêutica em Veterinária. Guanabara Koogan Rio de Janeiro, p. 717-757. 
Nascente, P.S. et al.

27. Spinosa, H.S.; Gorniak, S.L.; Bernardi, M.M. (2002). Farmacologia aplicada à Medicina Veterinária, 3rd Edition. Guanabara Koogan, Rio de Janeiro.

28. Stewart, L. (1990). Newly reported skin disease syndromes in the dog. Vet. Clin. North Am. Small Anim. Pract., 20 (6): 1603-1613.

29. Uchida, Y.; Nakade, T.; Kitazawa, K. (1990). In vitro activity of five antifungal agents against Malassezia pachydermatis. Nippon Juigaku Zasshi., 52, 851-853.
30. Vanden Bossh, H.; Engelen, M.; Rochette, F. (2003). Antifungal agents of use in animal health - chemical, biochemical and pharmacological aspects. J. Vet. Pharmacol. Therap., 26, 5-29.

31. Velegraki, A.; Alexopoulos, E.C.; Kritikou, S.; Gaitanis, G. (2004). Use of fatty acid RPMI 1640 media for testing susceptibilities of eight Malassezia species to the new triazole posaconazole and to six established antifungal agents by a modified NCCLS M27-A2 microdilution method and Etest. J. Clin. Microbiol., 42, 3589-3593. 